\title{
Use of psychographics in consumer market segmentation: the South African experience
}

\author{
Jacqui Spence, Russell Abratt* \& Bobby Amos Malabie \\ Graduate School of Business, University of the Witwatersrand, Johannesburg, P.O. Box 98, Wits, 2050 Republic of South Africa \\ AbrattR@Zeus.mgmt.wits.ac.za
}

Received February 1997

\begin{abstract}
This study examines the understanding and use of psychographics as a segmentation technique by advertising practitioners and marketers in South Africa. A comprehensive literature review of psychographics is undertaken. In addition, a review of segmentation techniques used in South Africa is given. A sample of 53 advertising agencies and 54 marketing professionals were studied. The results show that there is a low level of understanding of psychographics as a segmentation technique by both groups. The findings also show that there is no significant difference between marketing professionals and advertising practitioners in their understanding and utilization of psychographics as a segmentation technique. Although psychographics is used somewhat incorrectly by some marketers and advertising agencies, it is however normally used with other segmentation techniques, thus minimizing any mistakes that could result in incorrect targeting of markets.
\end{abstract}

*Author to whom correspondence should be addressed.

\section{Introduction}

Assisting marketers to identify and segment markets by using, amongst others, techniques like psychographics, is one of the most important roles of marketing decision makers, including advertising agencies. There is a growing need to go beyond demographic descriptors in analysing and selecting media. Increasingly, media vehicles are being chosen based on the characteristics of the life style of the audiences, or on the product or service usage patterns of these audiences. Notwithstanding this trend, the bulk of media audience data available to the media planner is based on demographics (Surmanek, 1993).

In South Africa, advertising agencies and their clients are confronted with rapidly changing and developing communities. Among other things, two factors compound the task of segmenting markets, firstly, the multi-cultural composition of the communities, and secondly, the fact that the different racial groups are largely at different levels of sophistication (SAARF, 1993).

The main objective of this article is to test the use and understanding of psychographics as a market segmentation technique by advertising agencies and marketers in the fast moving consumer goods industry.

\section{Conceptual development}

\section{Psychographics - a historical perspective}

The earliest mention of psychology in commercial terms was in 1859 by Gale of the University of Minnesota who tried to find the mental processes which go on in the minds of the consumers from the moment they see an advertisement until they have purchased the article advertised (Piirto, 1991). He further states that the development of personality assessment techniques was significant because they categorized people into types defined by personality traits, a concept that would provide the basis for psychographic research.

The following definitions provides the 'tone' of psychographics as a concept over time:

'The desire to match personalities with brands is irresistable. It is independent of history. It is independent of validity. It just keeps rolling along, like old man river' - Yankelovich (Piirto, 1991: 6).

'Psychographic information does as well or even better than focusing on product characteristics in certain categories where emotions are more deeply involved. When people yell out a brand name of a beer, they are saying something about who they are - when they say "Old Iron City", that's a little different than saying "Heineken"”- Haley (Piirto, 1991: 18).

'It is a creative tool that gives you a feeling for people you don't know personally' - Plummer (Piirto, 1991: 96).

'Psychographics is a way of getting to know a customer on a one-to-one basis' - Mather (Piirto, 1991: 96).

According to Wells (1974) the term 'psychographics' was used for the first time by Emanuel Demby during a speech in Chicago in 1969. Demby (1989:21) defined psychographics as the use of psychological, sociological and anthropological factors such as benefits desired (from the behaviour being studied), self concept, and lifestyle (or serving style) to determine how the market is segmented by the propensity of groups within the market - and their reasons - to make particular decisions about a product, person, ideology, or otherwise hold an attitude or use a medium.

The terms 'lifestyle' and 'psychographics' have sometimes been used interchangeably, and there is much overlap in what the terms are generally thought to mean. However, according to Nelson (1969), Dorney (1971) and Peterson (1972), the term 'psychographics' refers to studies that place comparatively heavy emphasis on generalized personality traits. On the other hand, analysts who have preferred the term 'lifestyle' have tended to focus either on broad cultural trends or on needs and values thought to be closely associated with consumer behaviour (Adler, 1970; Andreasen, 1967).

To this day there remains a great controversy amongst marketing academics and practitioners about what constitutes psychographics. Notwithstanding the multiple viewpoints, Weinstein (1994) takes the view that collectively the massed data provides meaningful marketing information. As a result, 
psychographic measurements are being used more frequently in market segmentation studies.

\section{Psychographics applied}

According to Wells, psychographics can make three different kinds of contribution to market segmentation studies.

'They can help describe existing market segments.

They can contribute new and useful segmentation var-

iables. Finally they can be used to develop new market segments' (1994: 325).

According to Wells \& Tigert (1971), as early as the 1950s, psychographics was preceded by a lively fad that came to be known as Motivation Research. Practitioners of Motivation Research used 'projective techniques' from clinical psychology and psychoanalysis to try to penetrate deeply into consumers' psyche in an effort to uncover the real reasons behind consumers' decision. According to Kassarjian (1971) many good marketing research studies have actually been critical of motivation research or experiments applying scientific procedures to motivation research. These advances in research methodologies led to the focus on consumer interests, activities, prejudices and opinions - and this has been variously called 'psychographic' research, 'lifestyle' research, and even (incorrectly) attitude research, however it did resemble motivation research in that a major aim was to draw recognizable human portraits of consumers but it also '... resembles the tougher-minded, more conventional research in that it is amenable to quantification and respectable samples' (Wells \& Tigert, 1971: 28).

Perhaps the most obvious use for this kind of research is that of drawing portraits of target groups in the advertising and marketing of products. If, according to Wells \& Tigert (1971), it is taken for granted that all forms of advertising and marketing are in some sense communication, psychographics measurement is a significant improvement over the sterile demographic profiles that have traditionally been in use in marketing. It is further asserted by Wells \& Tigert (1971) that whilst two products may have very similar demographic profiles, they may have usefully different psychographic profiles.

Ziff (1974) believes that demographics alone offers only limited help in market segmentation. Underlying the demographic attraction is what Ziff (1974: 132) calls '... the homogeneity myth ...' because it is based on the premise that demographic groups are relatively homogenous, therefore there is no need to use psychographics to flesh out distinct consumer behaviour. However it has been shown through experience that demographics only explains certain factors about potential consumer bases. It is argued that part of the attraction of psychographics is the ability to paint the bigger picture of consumers' lifestyles (Piirto, 1991). There is also the indication that psychographic segments which are developed for markets in one geographic location are generalizable to markets in other geographic locations (Lesser \& Hughes, 1986).

According to Kamakura \& Novak (1992), in the past few years there has been renewed interest among consumer researchers in the utilization of human values, interests and opinions as the basis for market segmentation. They, however, point out that human beings hold more than one value, interest or opinion, and these factors carry different levels of relevance in determining the motivations of each individual. Therefore it seems more reasonable to base one's definition of segments or comparisons of groups on this set of values rather than on the most important value held by each individual. Kamakura \& Novak (1992) further argue that in applying psychographics it is important to consider groups or identifiable segments rather than individuals.

Other methods like benefit segmentation use statistical analysis to group respondents on the basis of the importance that they attach to certain combinations of rational, sensory and emotional benefits expected from the product. However, according to Dhalla \& Mahatoo (1976), even when meaningful groups are extracted from the data, the benefits in most research studies are confined primarily to product attributes and do not cover the crucial areas of psychographics and communications behaviour. Furthermore, according to Dhalla \& Mahatoo (1976: 37), psychographics are crucial for discovering both the overt and the latent psycho-social motives that so often spell the difference between acceptance or rejection of the brand.

A cautionary note is advanced by Burns \& Harrison (1979) that psychographics were not meant to measure, in a precise manner, individual lifestyles, even though when aggregated, the results can be very useful in determining trends over time.

\section{Psychographics and communication}

\section{According to Plummer}

'the basic premise of psychographic research is that the more you know and understand about your customers the more effectively you can communicate and market to them' (1974: 33).

On the other hand, the more conventional and popular demographics have received broad acceptance and lend themselves easily to quantification and consumer classification. However demographics lack richness and often need to be supplemented with other data (Plummer, 1974). Furthermore, according to Greenberg \& McDonald (1989) whereas demographic segmentation seldom provides much guidance for product development or message strategies, psychographic research can identify similar values, attitude or lifestyle groups across cultural divides.

Hague (1991) believes in the theory that each and every product has particular appeal to a personality type. Understanding this theory is the starting point of an effective marketing campaign. The underlying idea is to match the product or service to a specific type or vice versa - psychographics measurement is intended to facilitate this process.

When embarking on psychographic research, Piirto (1991: 97) suggests that 'the work must be broad enough to uncover unique attitudes, emotions and images involving the specific product or brand'. Lazersfeld (1935: 26) further suggests that any research aimed at understanding consumer behaviour must involve an interplay among three broad sets of variables: predisposition, influences and product attributes.

Studies done by Dhalla \& Mahatoo (1976) show that in perceptual mapping, a map is prepared based on an individual's perceptions of competitive brands on certain product attributes. Segments can then be derived from these perceptions and preferences. However, these perceptual maps totally ignore psychographics and communication behaviour. 
Psychographics are therefore necessary because they can probe into specific product category and brand decisions by consumers (Weinstein, 1994), and as mentioned, psychographics can be used to paint the big picture of consumers' lifestyles (Piirto: 1991).

According to Ziff (1974), psychographics play a major role in the advertising prices, both in terms of strategy formation and actual communication. Dickson \& Ginter (1987) warn, however, that even if consumers shared common perceptions of a product's characteristics, it would be unusual to expect all consumers to respond equally to a market offering. To assist in predicting consumer reactions, psychographics can be used as a method of quantifying qualitative findings and value differences among consumers (Piirto, 1991).

\section{Psychographics and consumer behaviour}

Demby (1989) asserts that the basic purpose of psychographics is to humanize data by describing the human characteristics of consumers, that may have a bearing on their response to products, packaging, advertising and public relations efforts. Furthermore, an individual behaves in order to give positive expression to the type of person he/she is or perceives himself or herself to be. This aspect of psychographics is important because according to Dhalla \& Mahatoo (1976), brands today are the most universally acknowledged symbols of roles, and very often they are purchased not so much for their physical functions but as for the impressions they convey about their owners.

Because of the perceived limitations of demographics, many marketers have turned to psychology in an effort to understand consumers better regarding their behaviour towards brands, advertising and purchasing decisions (Dhalla \& Mahatoo, 1976).

According to Hustard \& Pessemier (1974), psychographic research implies a broad range of general psychological and personality measures. Most important is the fact that the most recurrent theme of the definitions of psychographics is the aim of understanding consumers and of drawing human portraits about them.

The accent on human behaviour is further provided by Reynolds \& Darden in their definition of psychographics as

the systematic use of relevant activity, interest and opinion constructs to quantitatively explore and explain the communicating, purchasing and consuming behaviours of persons for brands, products and clusters of products' (1974: 87).

Psychographics are therefore crucial for discovering the psycho-social motives that may influence the acceptance or rejection of a brand (Dhalla \& Mahatoo, 1976).

\section{Psychographics in the real world}

According to Wells (1975: 202), questions about psychographics can be classified under four main headings, namely: reliability, validity, applications to real-world marketing problems and contribution to the study of consumer behaviour.

Although Wells asserts that psychographic measurements and analytical procedures can have satisfactory reliability, he concedes that

'... generally satisfactory reliability does not imply

adequate reliability in all cases, and it may well be that some failures to find useful relationships between psychographics and consumer behaviour have been due to instability in the measurements themselves' (1975: 205).

As there is hardly any general agreement regarding the definition of psychographics; similarly the measurement validity depends upon what the questioner has in mind. However, according to Wells (1975), the evidence does show that psychographic variables generally relate to each other, to demographics, and to the use of products and media in ways that make perfectly good sense.

Wells further states that

'... the evidence on predictive validity shows that psychographic variables seldom account for large portions of the variable of individual behaviour. However this evidence also shows that psychographic variables are capable of producing substantial differences between groups of consumers, and that these differences are often larger than the differences produced by the standard demographic profile' (1975: 206).

\section{Application to marketing problems}

It is important to realize that in the real world the results of psychograpic research can be reliable and valid, and yet still not useful, particularly when relationships that should have been expected fail to appear. To advertising practitioners this is always a frustrating situation as it does not shed any new light nor help in the formulation of marketing or communication strategies.

However, psychographic segmentation is useful when it shows what needs the product meets within each group, and which brands are best at meeting them. With this information, the marketer can appeal directly and efficiently to the groups most apt to find his brand appealing, and can create new brands to fit need patterns which his brand cannot satisfy.

According to Lesser \& Hughes (1986), whereas early psychographic segmentation inventories were characterized by an emphasis on very generalized pattern of life statements, more contemporary inventories include statements relating to general and situation specific consumer shopping strategies and activities and benefits desires, which can provide more direction in developing actionable marketing strategies. This is obviously more useful for business people. According to Plummer (1986), no single population is homogenous, and the concept of the average man or woman is not helpful to marketing management as people are different and do things for different reasons. Thus there is a need to identify the differences and group them in such a way that a better understanding of the population under consideration emerges. Psychographic segmentation is therefore useful in that it moves beyond total scores or averages and reveals important differences that can be acted upon.

\section{Segmentation techniques used in South Africa}

The most common consumer segmentation techniques that have been available for use by marketers in South Africa are now presented. 


\section{Sociomonitor}

In 1976, Market Research Africa (MRA) embarked on the first phase of values and lifestyles research, which was called the Sociomonitor. The research has been conducted every year since, in white and urban black markets. According to Market Research Africa

'the Sociomonitor is described as follows: sociomonitor not only describes your market place, it permits you to understand it in a way that will enable you to improve the effectiveness of your marketing activities' (1995: B).

Firstly, it employs a larger than usual sample - 2000 respondents. Secondly, it covers a wide variety of subjects - demographics, lifestyle, media products and services - and all these can be interlinked with your specific interests.

Sociomonitor proceeds further by uncovering the personal value systems of the respondents. This step links their external behaviours to their inner motivations. It segments the market place, describes each segment in great detail in ways specifically relevant to your interests and it explains, in terms of value-based motivations, why your marketing attracts consumers, but not others. It also predicts how the market will react to your new marketing initiatives. Furthermore, sample sizes of 2000 ensure adequate representation, for statistical purposes, of all major brands and services. Of equal significance is the use of an area stratified probability sampling technique.

According to Culross (1995), the essence of the Sociomonitor is that it not only describes the market place, it permits the user to understand and improve the effectiveness of marketing activities, drawing human portraits of consumers. However, the main drawback is that it is based primarily on race as the main determinant.

\section{Living Standards Measure (LSM)}

Starting in the summer of 1988, the South African Advertising Research Foundation (SAARF) developed a new measure which was called the All Media Product Survey (AMPS) Living Standards Measure (LSM). The new measure had its origin in the realization that while the community size measure, which splits the population into groups according to the size of the community in which the members reside, was effective for this limited purpose, persons who live in similar community sizes differ with regard to their levels of disposable income, education, sophistication and general living standards, which could vary over a wide range. 'In particular, it became apparent that all rural dwellers were no longer (if they ever had been) living a simple, unsophisticated life style' (SAARF, 1993: 1). Furthermore it was felt that normal demographics such as community size, income and race were not a sufficiently discriminatory measure of 'sophistication'.

The LSM is largely based on AMPS data. According to Consumer scope (1994), from the large number of questions included in the AMPS survey, SAARF identified a short-list of thirteen variables which provide a good overall measure of standard of living.

Furthermore, according to Consumer scope

‘... while racial group, income and education are not among the short-list of variables, the LSM nevertheless correlates closely with such variables, illustrating an upward continuum in living standards from poor, predominantly rural and black have-nots, to educated and predominantly urban "affluents"' (1994: 1).

According to Smith (1995), the aim of the LSM was to find a segmentation tool that was stronger than a single demographic - it was aimed at improving media planning effectiveness rather than seeking to explain the motivations behind consumer habits.

Culross (1995) indicated that people use the term 'lifestyles' when they mean psychographics, in other words, there is great confusion regarding the terminology. However, he suggested that both marketers and advertising practitioners do perceive the need for psychographics, in an effort to improve their understanding of consumers and how to communicate with them effectively.

Furthermore, Culross (1994) mentioned that partly because the LSM is grounded in a judicious blend of data reflecting domestic living standards, economic status and urban facilities, it has rapidly established itself as a standard segmentation throughout the marketing industry. However, Culross (1995) points out that the LSM is by no means the panacea of marketers' segmentation woes as the LSM segments do not always make equally good marketing sense, that is, they are sometimes difficult to conceptualize as coherent market segments. However, in spite of the misgivings mentioned above, Culross (1994) is of the opinion that given the importance that LSMs have already achieved for South African marketers, it would be a pity to see their utility eroded. Culross (1994) further suggested that if there were a way of building psychographics into the LSM, the result would be the best of both worlds.

According to Langschmidt (1995), among other factors, the ease with which LSMs are used and the pervasive correlation displayed between the demographic and psychographic indicators, including wealth (income), status and cultural factors, has allowed for laziness on the part of advertisers - in other words, it has become a convenient shorthand for demographics and psychographics combined.

\section{Marketing bands}

Green \& Lascaris (1990: 36) stated that their preferred segmentation criteria that resulted in the marketing bands, was along the lines of education and occupation. Their primary motivation for selecting these criteria was that 'these criteria put emphasis on things that joined us, rather than on things that kept up apart ...' (Green \& Lascaris, 1990: 36). By using education and job status as division criteria, nine marketing bands were created. The result was that in the top marketing bands, that is, bands one to three, there were better educated people with responsible jobs while down in bands seven, eight and nine there were people with little or no education and unskilled jobs or no jobs at all. However, rather similarly to the LSMs, the segmentation resulted in whites being at the top of the scale with blacks at the bottom.

\section{Panel data}

Panel data, a consumer segmentation technique developed by Intregrated Marketing Research (1991: 3), may be described as follows: in summary, Landscape 91 provides effective coverage of South Africa's urban white population (that is 
90\% of SA white adults) and urban black adult population who are able to read English (that is $31 \%$ of SA black adult or $70.4 \%$ of SA urban black population).

The urban coverage of the South African black and white communities extends from metropolitan areas and cities to large and small towns, and villages as per AMPS definition. South Africa's two million strong coloured and Asian communities are currently excluded from the Panel data universe. It does not represent the two million urban black adults who are unable to read any English, or the 18.7 million black and 0.4 million white adults living in the rural areas of South Africa. As it stands, the Panel data data-base comprises survey results on some 2280 variables.

\section{Critical mass}

Critical Mass is a collection of slides that was prepared by Gous \& Coldwells (1990). The presentation dealt with the following: Black demographics, media selection for the Black market, effectiveness of radio commercials in the Black market and the source of data used was AMPS and Market Research Africa Surveys.

\section{Proposition development}

It has been argued by Wells (1974), Ziff (1974) and Kotler (1994), that the concept of demographics is generally understood by advertising practitioners. Indeed it is also commonly understood by people not ordinarily involved in the advertising and marketing industries to be concerned with age, income, education. The literature review shows clearly that there is a vast amount of information that demographics cannot provide, particularly concerning consumer motivations which results in their purchasing behaviour. It is therefore important that to increase the chances of successfully converting potential consumers to customers, the advertiser and/ or marketing executive is able to communicate with them in ways that will have a favourable impact on their purchasing decisions. This has led to the formulation of the following proposition:

P1: There is a low level of understanding of psychographics as a segmentation technique by both marketers and advertising practitioners.

It is further considered that, because of the suspected low level of understanding of psychographics as a segmentation technique, there is consequently a low level of its usage, hence the second proposition:

$\mathrm{P} 2$ : There is a low level of use of psychographics in the segmenting of consumer markets - by both marketing and advertising practitioners.

Although advertising and marketing professionals do not have similar training, or necessarily possess the same experience and background, it is argued that there is actually no difference between the two groups of professionals regarding their level of understanding of psychographics as a segmentation technique. Therefore the third proposition is:

P3: There is no significant difference between marketers and advertising practitioners in their understanding and utilization of psychographics as a segmentation technique.

\section{Methodology}

Sample

The study was conducted by surveying a sample of advertising agencies and companies in the fast moving consumer goods sector. The following sample delineation was used:

Advertising agencies currently operating in the greater Johannesburg metropolitan area. A population was obtained from Limelight Publications (1995). Manufacturing companies involved in the marketing and selling of fast moving consumer goods (fmcg), also operating in the greater Johannesburg metropolitan area. The population was obtained from the Johannesburg Chamber of Commerce Corporate Membership Listing.

The majority of 'fmcg' manufacturing and selling companies and advertising agencies work in partnership to develop communications and marketing strategies. It was felt that analysing and comparing the above organizations separately as sub-groups and as a whole would provide useful information that may be used to enhance and improve their efficiency.

Within the two groups mentioned above, it was decided that the study would be limited to staff in the following occupations: the advertising agency creative development and client service departments, and within the companies, marketing directors and managers, marketing service managers and brand managers.

The above occupations were deemed the most appropriate due to their intimate involvement in the development of communications and marketing strategies, a task that would often require the segmenting of consumers and the choice of target markets.

Advertising agencies accredited by the Association of Advertising Agencies (AAA) were used as the core base for the sample selection. The reason for this was because collectively these agencies accounted for over $90 \%$ of the national billing revenue during 1993 and also included a good spread of agencies from medium-sized to the largest agencies in South Africa (Advertising Focus, 1994).

According to Cory (1995), only full service agencies may apply for membership of the AAA. The following criteria must be fulfilled by the applying agency: the agency must have been operating for at least one year; it must have billings of a minimum of R5 million per annum; it must have a reasonable spread of clients - it must specifically not have $50 \%$ of its business resident with one client; and it must offer a full service, that is, creative, media and client functions.

Currently the AAA has thirty agencies in the greater Johannesburg area that are registered members. Fifty additional advertising agencies' names and addresses were obtained from Limelight Publications (1995). Advertising agencies not accredited by the AAA were considered on the basis of the agency having been in operation for at least a year.

A judgemental sample of 180 marketing professionals in the greater Johannesburg area was selected from the Chamber of Commerce Corporate Membership Listing. Primarily, companies with headquarters or marketing operations in the Johannesburg metropolitan area were targeted. The second criterion was to use the Advertising Focus (1994) publication to determine which companies incurred any advertising spend on their brands or products during 1993/1994. All of these 
companies were included in the sample. Furthermore, the manufacturing companies included in the sample were deemed to be medium to large organizations defined as such based on the number of employees rather than on turnover, number of product categories sold, or profit per annum. Any organization having 50 or more employees was deemed to constitute a medium to large company for the purposes of this study.

The procedure for selecting the respondents (within each organization) was as follows:

Each organization was telephoned as a preliminary measure, to ascertain the identities of the relevant personnel in the occupations chosen. Where possible the potential respondent was telephoned beforehand to solicit his/her participation in the research. The majority of the research questionnaires were faxed whilst the rest were hand-delivered. All the participating organizations were telephoned to confirm that the research questionnaire had been received, completed and could be collected or faxed back.

\section{Instrument}

The questionnaire was based on both the literature review and interviews conducted with randomly selected advertising and marketing experts, who were asked to look at the questionnaire and recommend any changes they deemed necessary. Only very minor changes in the language used were made. The questionnaire consisted of three sections.

The first section aimed at eliciting demographic information to facilitate structured analysis of the data. The second section was aimed at discovering the actual use of segmentation techniques. The third section was aimed at discovering the respondents' understanding of psychographics as a segmentation technique.

In section two, respondents were requested to list any psychographic segmentation techniques that they would use in the development of their marketing and communication strategies. The intention was to compile, spontaneously, a list of consumer segmentation techniques that respondents in the sample actually applied in their day-to-day work situations. It was felt that it was important to avoid spoon-feeding the respondents with information and thus introducing probable bias.

Respondents were then requested to indicate, from a provided list, segmentation techniques that they were most familiar with. There were no limitations as to the number of techniques they could choose; in fact, space was provided for them to include any other technique that may not have been included in the original list.

In section three respondents were requested to indicate, from a list of twelve constructs, what they believed to be a measure of psychographics. The twelve constructs were derived from the literature review. The literature review clearly indicated that there was no single universally accepted definition of psychographics. Different authors advanced their own favourite definition(s) of what constituted psychographics. However, according to Wells (1974), the common theme was that psychographics was designed to measure the following: the consumer's predisposition to buy a product, the influences that stimulate buying behaviour, and the relationship between the consumer's perception of product benefits and hisher lifestyle, interests and opinions.

Taking the approach that, collectively, the massed data pertaining to psychographics provides meaningful marketing information, the literature review was used as the basis for 20 statements numbered as statements $A$ to $T$ and used in the questionnaire.

In order to test the respondents' comprehension of psychographics as a segmentation technique, statements $B, D, H, I$, $\mathrm{O}, \mathrm{Q}$ and $\mathrm{T}$ were reversed so that they meant the opposite to what was intended by the original author (the result was a mix of true and false statements). The respondents were then requested to indicate the extent of their agreement or disagreement with the 20 statements mentioned above, regarding their application to psychographics.

\section{Data analysis}

The three propositions in this study were analysed in the following way:

\section{Proposition 1}

To check the level of understanding of psychographics as a segmentation technique, the respondents were requested to complete section 3 of the questionnaire. Using a well-known statistical package, Descriptive Statistics were used to discover the frequency of statements correctly or incorrectly identified.

Firstly, the aggregated scores of the entire sample were compared with original statements derived from the literature review and, secondly, the score achieved by the agency personnel and marketers were separately compared to the original statements derived from the literature review.

\section{Proposition 2}

To discover the level of use of psychographics in segmenting consumer markets, respondents were requested to complete section 2 of the questionnaire. A tally was made of what psychographic techniques were claimed to be used by both marketers and advertising practitioners. Firstly, a tally was made of the techniques used by the entire sample and then, separately of those used by agency and company groups.

\section{Proposition 3}

Proposition three was designed to establish whether there was any significant difference between marketers and advertising practitioners in their understanding and usage of psychographics as a segmentation technique. This was achieved by comparing the separate scores achieved by advertising and marketing practitioners for propositions one and two.

The Chi-squared test and t-tests were performed to discover whether there was any significant difference between the advertising and marketing practitioners' scores for sections 2 and 3 of the questionnaire.

\section{Limitations}

From the literature review it was clear that there was not a single universally accepted definition of psychographics or even applications thereof. Different authors advanced their own definition(s) of what constituted psychographics. It thus could be possible that the constructs and statements used in 
the questionnaire may generate possible dispute, and may challenge the validity of the results.

\section{Results and discussion}

Altogether 160 questionnaires were faxed or hand-delivered to 80 advertising agencies and 180 marketing professionals in fast moving consumer goods companies were sent the questionnaire. Altogether 53 responses from advertising agencies were received and 54 from companies, thus giving a $33 \%$ response rate from agencies and a $30 \%$ response rate from companies. A profile of the respondents is shown in Table 1.

The respondent profile shows that there was an almost even split between males and females. Most of the respondents were in the 25 to 49 year-old age group. As far as service in their organization is concerned, $44 \%$ had between one and five years service and $33 \%$ had less than a year's service. This indicates a relatively high staff turnover and is considered to be normal in advertising agencies and to some extent in the fast moving consumer goods companies. As far as occupations are concerned, in the advertising agencies there was a good spread between the creative and client service departments. In the companies, the vast majority of respondents were either brand managers or marketing managers. This profile thus represents the typical professional manager found in both agencies and companies.

\section{Use of segmentation techniques}

Respondents were requested to spontaneously mention the psychographic segmentation techniques that they applied in their work situations. The LSMs received 81 mentions, Sociomonitor 20, Marketing bands 2, Panel data 5 and 29 other mentions, none of which were used frequently. The fact that the highest mentions were for the LSMs, which according to Smith (1995) is not a psychographic segmentation technique, strongly suggests that the LSM is either deliberately or ignorantly being used as a psychographic segmentation technique by both the advertising and marketing practitioners.

When prompted, the respondents were asked what segmentation techniques they were most familiar with, the LSM got 103 mentions, Sociomonitor 67, Marketing bands 28, Panel data 27, Critical mass 20, SABC match 8 and others got 17 mentions.

\begin{tabular}{|c|c|c|c|c|c|c|}
\hline Gender & $\begin{array}{c}\text { Male } \\
\%\end{array}$ & $\begin{array}{c}\text { Female } \\
\%\end{array}$ & & & & \\
\hline & 52 & 48 & & & & \\
\hline \multirow[t]{3}{*}{ Age } & $18-24$ & $25-34$ & $35-49$ & $50+$ & & \\
\hline & no. & no. & no. & no. & & \\
\hline & 14 & 56 & 34 & 3 & & \\
\hline & $<$ than 1 & $1-5$ years & Over 5 yrs & & & \\
\hline \multirow[t]{2}{*}{ Service } & year $\%$ & $\%$ & $\%$ & & & \\
\hline & 44 & 23 & 33 & & & \\
\hline \multirow[t]{3}{*}{ Occupation } & $\begin{array}{l}\text { Creative } \\
\text { director }\end{array}$ & $\begin{array}{l}\text { Client } \\
\text { service }\end{array}$ & $\begin{array}{l}\text { Marketing } \\
\text { director }\end{array}$ & $\begin{array}{l}\text { Marketing } \\
\text { manager }\end{array}$ & $\begin{array}{c}\text { Brand } \\
\text { manager }\end{array}$ & $\begin{array}{c}\text { Marketing } \\
\text { services }\end{array}$ \\
\hline & $\%$ & $\%$ & $\%$ & $\%$ & $\%$ & $\%$ \\
\hline & 22 & 29.8 & 3 & 15 & 28 & 4 \\
\hline
\end{tabular}

\begin{tabular}{|c|c|c|c|c|}
\hline \multirow[t]{2}{*}{ Technique } & \multicolumn{2}{|c|}{ Familiarity } & \multicolumn{2}{|c|}{ Usage } \\
\hline & Number & $\%$ & Number & $\%$ \\
\hline$\overline{\mathrm{LSM}}$ & 103 & 96 & 81 & 76 \\
\hline Sociomonitor & 67 & 63 & 20 & 19 \\
\hline Marketing bands & 28 & 26 & 2 & 2 \\
\hline Panel data & 27 & 25 & 5 & 5 \\
\hline$n=107$ & & & & \\
\hline
\end{tabular}

Table 2 contrasts the respondents familiarity with available segmentation techniques and the actual usage of them.

LSMs and Sociomonitor have the highest awareness and usage rates as segmentation techniques. Langschmidt (1995) has argued that, among other factors, the LSM's ease of use and the pervasive correlation displayed between the demographic and psychographic indicators has encouraged both advertising and marketing practitioners to use the LSM as a convenient shorthand for demographics and psychographics combined. Langschmidt (1995) indicated that this was caused by the lack of understanding of psychographics as a segmentation technique by a sizeable proportion of the users of these segmentation techniques.

\section{Identification of psychographic measures}

The respondents were requested to identify from a list of constructs, those that they believed could be described as a measure of psychographics. This is shown in Table 3.

Using the assumption that at least $50 \%$ of the sample correctly identified the measures as psychographic ones, the following were correct: lifestyles, attitudes, values, opinions, perceptions and marketing behaviour (by the companies only). Incorrectly identified psychographic measures were: living standards, status, cultural factors, psychometrics and wealth (by the agencies only).

\begin{tabular}{|c|c|c|c|c|c|c|}
\hline \multirow[b]{2}{*}{ Measures } & \multicolumn{4}{|c|}{ Correctly identified responses } & \multirow[b]{2}{*}{$x^{2} \alpha 0.05$} & \multirow[t]{2}{*}{ Result } \\
\hline & Agencies & $\%$ & Companies & $\%$ & & \\
\hline Lifestyle & 47 & 89 & 51 & 94 & 1.1540 & Accept \\
\hline Demographics & 30 & 57 & 37 & 69 & 1.6221 & Accept \\
\hline Attitudes & 47 & 89 & 49 & 91 & 0.1232 & Accept \\
\hline Wealth & 23 & 43 & 28 & 52 & 0.2285 & Accept \\
\hline Psychometrics & 22 & 42 & 22 & 41 & 0.0076 & Accept \\
\hline Values & 45 & 85 & 45 & 83 & 0.0495 & Accept \\
\hline $\begin{array}{l}\text { Marketing } \\
\text { behaviour }\end{array}$ & 25 & 47 & 32 & 59 & 1.5704 & Accept \\
\hline Living standards & 16 & 30 & 14 & 26 & 0.2409 & Accept \\
\hline Status & 13 & 25 & 15 & 28 & 0.1462 & Accept \\
\hline Cultural factors & 9 & 17 & 9 & 17 & 0.0019 & Accept \\
\hline Opinions & 40 & 75 & 40 & 74 & 0.0277 & Accept \\
\hline Perceptions & 40 & 75 & 40 & 74 & 0.0277 & Accept \\
\hline \multicolumn{7}{|l|}{$n=53 ; n=54$} \\
\hline \multicolumn{7}{|c|}{ Accept Ho if $x^{2}<3.843$} \\
\hline \multicolumn{7}{|c|}{ Reject Ho if $x^{2}>3.843$} \\
\hline
\end{tabular}


According to Wells (1974) and Demby (1989), the following group of variables comprising lifestyle, attitudes, values, perceptions and opinions are the mainstay of psychographic measures. The respondents concurred with the literature in this regard. Demographics are not used to measure psychographics (Wells, 1975; Kotler, 1994). Only 57\% of the advertising practitioners and $60 \%$ of the companies concurred with them. These results may be on the low side, as demographics are generally thought to be understood by advertising and marketing practitioners. According to Langschmidt (1995), wealth, status and cultural factors have no bearing on psychographic research. However, a high proportion of the respondents, at least $75 \%$, were of the view that status and cultural factors were measures of psychographics. Piirto (1991) stated that psychographic research has successfully been used to indicate accurately the views or marketing behaviour of individuals as well as the population at large. Concerning the respondents only $47 \%$ of the agencies and $59 \%$ of the companies concurred with the literature. Regarding psychometrics, Piirto (1991) stated that these techniques are based on psychological analysis which may include quantifiable tests de- signed to measure psychographic variables such as values and perceptions. Only $42 \%$ of the agencies and $41 \%$ of the companies correctly identified psychometrics as a psychographic measure. Smith (1995) stated that living standards is not a psychographic measure. However, $70 \%$ of the advertising agencies and $74 \%$ of the companies incorrectly identified liv. ing standards as a measure of psychographics.

The $\mathrm{Chi}^{2}$ statistic was used to test the null hypothesis, that is, there was no significant difference between advertising agencies and companies in their understanding of psychographic measures. The results in Table 3 show there is no significant difference between advertising agencies and the companies in the sample.

\section{Identification of psychographic statements}

A list of twenty statements was provided which described situations or conditions where psychographics may or may not be applicable. The respondents were requested to indicate their degree of agreement or disagreement with these statements. The results are shown in Table 4.

\begin{tabular}{|c|c|c|c|c|c|c|}
\hline & \multirow[t]{2}{*}{ Statements } & \multicolumn{4}{|c|}{ Correctly identified responses } & \multirow[b]{2}{*}{ Values } \\
\hline & & $\begin{array}{c}n=53 \\
\text { agencies }\end{array}$ & $\%$ & $\begin{array}{l}n=54 \\
\text { companies }\end{array}$ & $\%$ & \\
\hline $\mathbf{A}$ & $\begin{array}{l}\text { Psychographics may be viewed as the practical application of the behavioural and } \\
\text { social sciences to marketing research }\end{array}$ & 45 & 84.9 & 45 & 83.3 & 0.5773 \\
\hline B & Psychographics is a quantitative research procedure & 11 & 20.8 & 14 & 25.9 & 0.1010 \\
\hline c & Psychographics seeks to describe the human characteristics of consumers & 46 & 88.7 & 48 & 88.9 & 0.7571 \\
\hline D & $\begin{array}{l}\text { Psychographics is primary research and is a more complex approach to obtaining } \\
\text { information }\end{array}$ & 26 & 49.1 & 36 & 66.7 & 0.4393 \\
\hline$E$ & $\begin{array}{l}\text { Psychographics research implies a broad range of general psychological and person- } \\
\text { ality measures }\end{array}$ & 47 & 88.7 & 43 & 79.6 & 0.4663 \\
\hline $\mathbf{F}$ & Psychographic research is the same as attitude research & 12 & 22.6 & 10 & 18.5 & 0.9142 \\
\hline G & Psychographics communicates consumer characteristics better than demographics & 34 & 64.2 & 33 & 61.1 & 0.3996 \\
\hline $\mathbf{H}$ & $\begin{array}{l}\text { Psychographics does play a major role in the advertising process, both in terms of } \\
\text { strategy formulation and actual communications }\end{array}$ & 48 & 90.6 & 46 & 85.2 & 0.6950 \\
\hline I & Psychographics add a useful increment to the standard demographic profile & 33 & 62.3 & 31 & 57.4 & 0.9000 \\
\hline $\mathbf{J}$ & $\begin{array}{l}\text { Psychographics probe into specific product caregory and brand decisions by } \\
\text { consumers }\end{array}$ & 27 & 50.9 & 21 & 38.9 & 0.2897 \\
\hline $\mathbf{K}$ & $\begin{array}{l}\text { Psychographics are valuable in showing marketers a new way to think about markets } \\
\text { and gives advertising people a way to understand human beings }\end{array}$ & 43 & 81.1 & 49 & 90.7 & 0.2585 \\
\hline $\mathbf{L}$ & $\begin{array}{l}\text { Knowing customers psychographics is the most essential part of effectively commu- } \\
\text { nicating with them }\end{array}$ & 38 & 71.7 & 39 & 72.2 & 0.7637 \\
\hline $\mathbf{M}$ & Psychographics is a method of quantifying qualitative findings & 15 & 28.3 & 11 & 20.4 & 0.2027 \\
\hline $\mathbf{N}$ & $\begin{array}{l}\text { Psychographics research can identify similar values, attitude or lifest yle groups across } \\
\text { cultures }\end{array}$ & 50 & 94.3 & 49 & 90.7 & 0.4396 \\
\hline o & Psychographics allow us to view a population as individuals & 39 & 73.6 & 29 & 53.7 & 0.0094 \\
\hline $\mathbf{P}$ & $\begin{array}{l}\text { Psychographics are crucial for discovering both the overt and the latent psycho-social } \\
\text { motives that so often spell the difference between accepting or rejecting a brand }\end{array}$ & 38 & 71.7 & 40 & 74.1 & 0.4549 \\
\hline Q & $\begin{array}{l}\text { Psychographics segments which are developed for markets in one geographic location } \\
\text { are generalizable to markets in other geographic locations }\end{array}$ & 18 & 34.0 & 18 & 33.3 & 0.7431 \\
\hline $\mathbf{R}$ & Psychographics have added to the predictive ability of demographics & 32 & 60.4 & 35 & 64.8 & 0.3561 \\
\hline $\mathbf{S}$ & $\begin{array}{l}\text { Psychographics market research involves the use of anthropological factors to deter- } \\
\text { mine how the market is segmented by the propensity of groups within the market to } \\
\text { make a particular decision about products and services }\end{array}$ & 22 & 41.5 & 24 & 44.4 & 0.4981 \\
\hline $\mathbf{T}$ & $\begin{array}{l}\text { Demographic segmentation seldom provides much guidance for product development } \\
\text { or message strategies }\end{array}$ & 43 & 81.1 & 47 & 87.0 & 0.3221 \\
\hline
\end{tabular}


Statements A,C,E,G,H,I,J,K,L,N,O,P,R and T were correctly identified by at least $50 \%$ of the respondents. Both groups of respondents incorrectly identified statements $M, Q$ and $S$, while advertising agencies also incorrectly identified $B$ and $\mathrm{D}$ and companies incorrectly identified $\mathrm{F}$ and $\mathrm{J}$.

The t-test was used to test the null hypothesis. There is no significant difference between advertising agencies and companies in their understanding and usage of psychographics as a segmentation technique. The results indicate acceptance of the null hypothesis.

\section{Conclusion}

The first proposition was designed to establish the level of understanding of psychographics as a segmentation technique. The proposition stated that there is a low level of understanding of psychographics as a segmentation technique by both marketers and advertising practitioners. The findings show that we must accept this proposition.

The second proposition was developed to find out the level of use of psychographics in segmenting consumer markets. The proposition stated there is a low level of use of psychographics in the segmenting of consumer markets by both marketing and advertising practitioners. This proposition must be rejected as there is a high level of use of psychographic segmentation; although some of the techniques used are definitely incorrect according to the literature.

The third proposition stated that there is no significant difference between marketers and with other segmentation techniques, thus minimizing any mistakes that could result in incorrect targeting of markets.

While psychographic segmentation does take place, it is used together with other segmentation techniques like demographics. This is a correct way of approaching the target market decision because there is still too much confusion and disagreement on what psychographics really is. What is really needed is a comprehensive review of the definition of psychographics.

\section{References}

Adler, L. 1970. Cashing-in on the Cop-out, Business Horizons, 13: 19-30.

Andreasen, A.R. 1967. Leisure, mobility and lifestyle patterns. In Moyer, R. (ed.). Changing marketing systems. Chicago: American Marketing Association.

Burns, A.C. \& Harrison, M.C. 1979. A test of the reliability of psychographics, Journal of Marketing Research, 16: 32-38.

Consumer scope. 1994. Bringing LSMs to life, Integrated Marketing, Rivonia, Johannesburg.

Culross, B. 1994. Tacking to meet the winds of change - reflections on cross-cultural research, Market Research Africa.

Demby, E.H. 1989. Psychographics Revisited: The Birth of A Technique, Marketing News, p. 21.

Dhalla, N.K. \& Mahato, W.H. 1976. Expanding the scope of segmentation research, Journal of Marketing, 40: 34-41.

Dickinson, P.R. \& Ginter, J.L. 1987. Market segmentation, product differentiation, and marketing strategy, Journal of Marketing, 51 : 1-10.

Dorny, L.R. 1971. Observations on psychographics. In King, C. \& Tigert, D. (eds.). Attitude research reaches new heights. Chicago: American Marketing Association, pp. 200-201.

Gous, C. \& Coldwells, B. 1990 . Reaching critical mass: a management report. Johannesburg: SABC Advertising Services.
Green, N. \& Lascaris, R. 1990. Communications in the Third World. Cape Town: Human \& Rousseau (Pty) Ltd and Tafelberg Publishers Ltd.

Greenberg, M. \& McDonald, S.S. 1989. Successful needs/benefits segmentation: a user's guide, Journal of Consumer Marketing, 6 : 29-36.

Hague, P. 1991. Business Marketing Digest (IMD), 2, Second Quarter, pp. 67-72.

Hustaad, T.P. \& Pessemier, E.A. 1974. The development of psychographic life style and associated activity and attitude measures. In Wells, W.D. (ed.). Lifestyle and psychographics. Chicago: American Association, pp 31-70.

Integrated marketing research. 1991. Landscape 91 : an urban market structure paradigm, Integrated Marketing, Rivonia, Johannesburg.

Kamakura, W.A. \& Novak, T.P. 1992. Value-system segmentation: exploring the meaning of LOV, Journal of Consumer Research, 19: 119-132.

Kassarjian, H.H. 1971. Personality and consumer behaviour: a review, Journal of Marketing Research, 8: 409-417.

Kotler, P. 1994. Marketing Management: analysis, planning, implementation and control, 8th 4dition. New Jersey: A Paramount Communications Company.

Lazersfeld, P.F. 1935. The art of asking why, National Marketing Review, 1: 26-38.

Lesser, J.A. \& Hughes, M.A. 1986. The generalisability of psychographic market segment across geographic location, Journal of Marketing, 50: 18-27.

Limelight Publications. 1995. Contacts 1995, Volume 18, Johannesburg: pp 22-32.

Nelson, A.R. 1969. A national study of psychographics. Unpublished paper delivered at the International Marketing Congress, American Marketing Association, June, 1969.

Peterson, R.A. 1972. Psychographics and media exposure, Journal of Advertising Research, 12: 17-20.

Piirto, R. 1991. Beyond mind games: the marketing power of psychographics. New York: American Demographics Books.

Plummer, J.T. 1974. The concept and application of life-style segmentation, Journal of Marketing, January: 33-34.

Reynolds, F.D. \& Darden, W.R. 1974. Construing life style and psychographics. In Wells, W.D. (ed.). Lifestyle and psychographics. Chicago: American Association, pp. 71-95.

S.A.A.R.F. 1993. The South African Advertising Research Foundations Living Standards Measure (LSM). South African Advertising Research Foundation, November.

Market Research Africa. 1995. Welcome to Sociomonitor, Sociomonitor Futures, Johannesburg, pp. A-J.

Surmanek, J. 1993. Introduction to advertising media Illinois: NTC Business Books.

Weinstein, A. 1994. Market segmentation, revised edition. Chicago: Probus Publishing Company.

Wells, W.D. 1974. Lifestyle and psychographics.Chicago: American Marketing Association.

Wells, W.D. 1975. Psychographics: a critical review, Journal of Marketing Research, 12 May: 196-209.

Wells, W.D. \& Tigert, D.J. 1971. Activities, interests and opinions, Journal of Advertising Research, 11: 27-35.

Ziff, R. 1974. The role of psychographics in the development of advertising strategy and copy. In Wells, W.D. (ed.). Lifestyle and psychographics. Chicago: American Association, pp 31-70. 